\title{
A percepção dos professores sobre a inclusão no ensino remoto dos alunos com deficiência durante a pandemia do novo coronavírus
}

\author{
The perception of teachers about the inclusion in the remote teaching of students with disabilities
} during the new coronavirus pandemic

La percepción de los profesores sobre la inclusión en la enseñanza a distancia de estudiantes con discapacidad durante la nueva pandemia de coronavirus

Polliane de Jesus Dorneles Oliveira ${ }^{1}$

ORCID: https://orcid.org/0000-0001-9660-7760 Instituto Federal de Educação, Ciência e Tecnologia de Minas Gerais, Brasil E-mail:polliane01@gmail.com

Walter Pinto de Oliveira ${ }^{2}$

ORCID: https://orcid.org/0000-0002-5123-9092 Instituto Federal de Educação, Ciência e Tecnologia de Minas Gerais, Brasil E-mail: walterbeyn@gmail.com

Rosemary P. Costa e Barbosa ${ }^{3}$

ORCID: https://orcid.org/0000-0001-5368-2162 Instituto Federal de Educação, Ciência e Tecnologia de Minas Gerais, Brasil E-mail:rose.costa@ifmg.edu.br

\begin{abstract}
Resumo
A pandemia do novo coronavírus trouxe para a educação o desafio do ensino remoto. As escolas estão adaptando suas ações para atender a esta forma de ensino não usual no seu cotidiano. Diante deste contexto emerge a indagação sobre como está sendo feita a inclusão dos alunos com deficiência nesta modalidade de ensino. Assim, o presente artigo objetivou analisar a inclusão dos alunos com deficiência durante o período da Pandemia do Novo Coronavírus no âmbito da Educação Básica. Utilizou-se uma pesquisa exploratória com uma abordagem qualitativa que teve como instrumento um questionário semiestruturado. Os sujeitos de pesquisa foram 52 professores matriculados na Pós-graduação em Docência, com ênfase na educação básica e educação inclusiva, do IFMG campus Arcos. Observou-se na pesquisa que, na percepção dos professores, grande parte dos alunos com deficiência, estão fora de um contexto educacional neste momento. Dentre os motivos para estes alunos não estarem sendo acompanhados pela escola, ou acompanhados de forma precária estão a falta de acesso à tecnologia; dificuldade de acompanhamento pela família e/ou responsável e as atividades não adaptadas para os alunos com deficiência. Conclui-se que a Pandemia do novo Coronavírus agravou o cenário de exclusão escolar para os alunos com deficiência.
\end{abstract}

Palavras-chave: Ensino remoto; Inclusão escolar; Deficiência; Coronavírus; Exclusão.

\begin{abstract}
The pandemic of the new coronavirus brought the challenge of remote education to education. Schools are adapting their actions to meet this unusual form of teaching in their daily lives. In this context, the question arises as to how the inclusion of students with disabilities in this type of teaching is being carried out. Thus, this article aimed to analyze the inclusion of students with disabilities during the New Coronavirus Pandemic period in the scope of Basic Education. An exploratory research with a qualitative approach was used, using a semi-structured questionnaire as an instrument. The research subjects were 52 teachers enrolled in the Graduate Program in Teaching, with an emphasis on basic
\end{abstract}

\footnotetext{
${ }^{1}$ Mestranda em Educação Tecnológica do CEFET-MG. Pós-graduanda do Curso de Especialização em Docência com Ênfase na Educação Inclusiva - Instituto Federal de Educação, Ciência e Tecnologia de Minas Gerais (IFMG) - Arcos - MG - Brasil. Graduada em Psicologia pela Pontifícia Universidade Católica de Minas Gerais e Pedagoga pela Universidade Estácio de Sá. E-mail: polliane01@gmail.com

${ }^{2}$ Pós-graduando do Curso de Especialização em Ênfase na Educação Inclusiva - Instituto Federal de Educação, Ciência e Tecnologia de Minas Gerais (IFMG) - Arcos - MG - Brasil. Graduado em Ciências Econômicas pela Pontifícia Universidade Católica de Minas Gerais, Ciências Contábeis pelo Centro Universitário Newton Paiva e Licenciatura em Matemática pela Faculdade Educacional da Lapa. E-mail: walterbeyn@gmail.com

${ }^{3}$ Dra. em Ciências / UNIFESP; Psicóloga - Profa. do Instituto Federal de Educação, Ciência e Tecnologia de Minas Gerais (IFMG) - Campus Bambuí - MG - Brasil. E-mail: rose.costa@ifmg.edu.br
} 
education and inclusive education, at the IFMG campus Arcos. It was observed in the research that, in the perception of teachers, a large part of students with disabilities are out of an educational context at this time. Among the reasons for these students not being accompanied by the school or accompanied in a precarious way are the lack of access to technology; difficulty in monitoring by the family and / or guardian and activities not adapted for students with disabilities. It is concluded that the Pandemic of the new Coronavirus worsened the scenario of school exclusion for students with disabilities.

Keyword: Remote education; School inclusion; Deficiency; Coronavirus; Exclusion.

\section{Resumen}

La pandemia del nuevo coronavirus trajo a la educación el desafío de la educación a distancia. Las escuelas están adaptando sus acciones para enfrentar esta forma inusual de enseñanza en su vida diaria. En este contexto, surge la pregunta de cómo se está llevando a cabo la inclusión de estudiantes con discapacidad en este tipo de docencia. Así, este artículo tuvo como objetivo analizar la inclusión de estudiantes con discapacidad durante el período de la Nueva Pandemia del Coronavirus en el ámbito de la Educación Básica. Se utilizó una investigación exploratoria con enfoque cualitativo, utilizando como instrumento un cuestionario semiestructurado. Los sujetos de investigación fueron 52 profesores matriculados en el Programa de Posgrado en Docencia, con énfasis en educación básica y educación inclusiva, en la IFMG campus Arcos. En la investigación se observó que, en la percepción de los docentes, una gran parte de los estudiantes con discapacidad se encuentran fuera de un contexto educativo en este momento. Entre las razones por las que estos estudiantes no están acompañados por la escuela, o acompañados de manera precaria están la falta de acceso a la tecnología; dificultad en el seguimiento por parte de la familia y / o tutor y actividades no adaptadas para estudiantes con discapacidad. Se concluye que la Pandemia del nuevo Coronavirus agravó el escenario de exclusión escolar para estudiantes con discapacidad.

Palabra clave: Educación a distancia; Inclusión escolar; Deficiencia; Coronavirus; Exclusión.

\section{Introdução}

A educação é elemento que faz parte de um conjunto de direitos garantidos a todas as pessoas, dever do Estado e da família, segundo o art. 205 da Constituição Federal (CF) de 1988, esses direitos são chamados de direitos sociais. Eles têm como objetivo o valor da igualdade entre as pessoas. Para regulamentar os direitos das pessoas com deficiência, já inclusas no art. 205, temos ainda o Decreto $\mathrm{n}^{\circ} 6.949$ de 25 de agosto de 2009, que promulga as pessoas com deficiência o direito de acesso a um sistema educacional inclusivo, seja ele em todos os níveis, intelectuais e do conhecimento.

Ao refletirmos sobre a inclusão devemos pensar, dentre outros aspectos, na formação dos professores e experiência no trabalho com esses alunos, pois, ela é importante nas estratégias construídas para a inclusão destes alunos. Ao discorremos sobre a formação e experiência dos professores torna-se mister salientar o atual momento no qual o mundo está vivendo em relação a pandemia do Coronavírus. Vale ressaltar que essa formação e experiência se fazem necessárias principalmente neste momento, pois, impacta na forma como vem sendo realizada a inclusão e aprendizagem dos alunos com NEEs no ensino remoto. Devemos refletir sobre como tem sido o ensino e a aprendizagem dos alunos de inclusão neste momento.

Sabemos que a partir de março de 2020 iniciou-se a quarentena no Brasil. As aulas presenciais foram suspensas e em muitas escolas, metodologias alternativas, como as aulas remotas foram iniciadas por meio virtual. O ensino remoto foi instituído em várias escolas sendo praticado com o uso de tecnologias, sendo autorizado pela Portaria №343, de 17 de março de 2020 em caráter temporário pelo Ministério da Educação (MEC), para que o cronograma presencial fosse cumprido de maneira online com o intuito de amenizar os prejuízos referente a aprendizagem dos alunos.

Assim, partindo do interesse pelo tema e da reflexão ora explicitada, perguntamos: Como tem sido realizada a inclusão dos alunos com NEEs durante todo esse período da pandemia? Como esses alunos têm sido assessorados no período de pandemia e quais os mecanismos de inclusão têm sido utilizados para que esse aluno esteja incluído em sua turma regular?

Nessa perspectiva a artigo objetivou analisar a inclusão dos alunos com deficiência durante o período da Pandemia do Novo Coronavírus no âmbito da Educação Básica. Com este intuito foram abordados os seguintes objetivos específicos: analisar a legislação e as políticas sobre os serviços prestados a estudantes com alguma NEEs durante a pandemia; verificar o uso, pelos 
professores, de Tecnologia Assistiva (TA) com os alunos com NEEs durante a Pandemia e descrever como os alunos com NEEs têm sido incluídos nas aulas durante a Pandemia.

\subsection{Pandemia e Inclusão}

Ao pensarmos na inclusão e em seus marcos históricos, poderíamos pensar em uma linha do tempo iniciada em 1988, com a promulgação da Constituição Federal, no seu art. 208 que ressalta o "atendimento educacional especializado aos portadores de deficiência, preferencialmente na rede regular de ensino" (Brasil, 1988). Sendo o dever do Estado oferecer o atendimento educacional especializado (AEE), preferencialmente na rede regular de ensino e não mais apartado, com ações isoladas e separado das turmas regulares de ensino.

$\mathrm{Na}$ década de 90, pode-se verificar que a diversidade humaniza a sociedade, quando essa respeita as singularidades existentes. Dessa maneira, a lei n ${ }^{\circ}$ 8.069, de 13 de julho de 1990, dispõe sobre o Estatuto da Criança e do Adolescente (ECA), no seu art. $3^{\circ}$ ressalta que a criança e o adolescente gozam de todos os direitos fundamentais inerentes à pessoa humana, sem qualquer tipo de distinção ou exclusão. Assegurando a todos, por lei, as oportunidades e facilidades, a fim de amparar o desenvolvimento físico, mental, moral, espiritual e social em condições de liberdade e dignidade.

No ano de 1994, a Portaria MEC n ${ }^{\circ} 1.793$ de dezembro de 1994, no art. $1^{\circ}$ recomenda a inclusão da disciplina aspectos ético-político-educacionais da normalização e integração da pessoa portadora de necessidades especiais, prioritariamente, nos cursos de Pedagogia, Psicologia e em todas as Licenciaturas. (BRASIL, 1994, online). Nesse mesmo ano a Conferência Mundial sobre a Necessidades Educativas Especiais, realizada pela UNESCO, em Salamanca (Espanha), em junho de 1994, objetivou discutir o acesso e a qualidade do ensino e teve como foco a discussão da atenção educacional dos alunos com necessidades educacionais especiais.

No ano de 1996, temos Lei no 9.394 de 20 de dezembro de 1996, Lei de Diretrizes e Bases da Educação Nacional (LDBN), no qual os municípios brasileiros receberam a responsabilidade da universalização do ensino para as pessoas entre 0 aos 14 anos de idade, ou seja, a oferta da educação infantil e fundamental para todas as crianças e jovens que residem no território nacional. Em seu capítulo V, aborda a educação Especial definindo-a como a modalidade de educação escolar oferecida preferencialmente na rede regular de ensino, para educandos com deficiência, transtornos globais do desenvolvimento e altas habilidades ou superdotação (LDBN, 1996, online), sendo a redação dada pela Lei no 12.796, de 4 de abril de 2013.

Em 1999 a convenção da Guatemala no seu artigo I, define o termo deficiência como: uma restrição física, mental ou sensorial, de natureza permanente ou transitória, que limita a capacidade de exercer uma ou mais atividades essenciais da vida diária causada ou agravada pelo ambiente econômico e social (BRASIL, 1999, online). Essa convenção foi um avanço para a inclusão, pois a partir dela todas as formas de discriminação contra as pessoas com necessidades especiais deveriam sem eliminadas.

Ainda no ano de 1999, o Decreto n 3.298 de 20 de dezembro, regulamenta a Lei n 7.853 , dispõe sobre a Política Nacional para a Integração da Pessoa Portadora de Deficiência, esse termo não é mais utilizando sendo modificado por pessoa com deficiência. O Decreto estabelece a matrícula compulsória de pessoas com deficiência, em cursos regulares, a consideração da educação especial como modalidade de educação escolar perpassando por todos os níveis e modalidades de ensino, sendo a oferta obrigatória e gratuita da educação especial em estabelecimentos públicos de ensino (BRASIL, 1999, online).

A lei $\mathrm{n}^{\mathbf{0}}$ 10.098, de 19 de dezembro de 2000, institui normas e critérios básicos para promover a acessibilidade das pessoas com deficiência ou que tenham alguma mobilidade reduzida, destaca em seu art. $1^{\circ}$ que:

Esta Lei estabelece normas gerais e critérios básicos para a promoção da acessibilidade das pessoas portadoras de deficiência ou com mobilidade reduzida, mediante a supressão de barreiras e de obstáculos nas vias e espaços públicos, 
no mobiliário urbano, na construção e reforma de edifícios e nos meios de transporte e de comunicação (BRASIL, 2000, online).

Em 2001, a Lei 10.172 de 9 de janeiro, aprova o Plano Nacional de Educação que estabelece objetivos e metas para a Educação das pessoas com NEE. Em 8 de outubro de 2001, o Brasil através do Decreto 3.956, promulgou a Convenção Interamericana para a Eliminação de Todas as Formas de Discriminação Contra as Pessoas Portadoras de Deficiência. Esse decreto traz uma explanação sobre a questão da discriminação ao que referindo-se às pessoas com deficiência, ressaltando a definição do termo:

Significa toda diferenciação, exclusão ou restrição baseada em deficiência, antecedente de deficiência, consequência de deficiência anterior ou percepção de deficiência presente ou passada, que tenha o efeito ou propósito de impedir ou anular o reconhecimento, gozo ou exercício por parte das pessoas portadoras de deficiência de seus direitos humanos e suas liberdades fundamentais (BRASIL, 2001, online).

Assim, esse decreto vem para reafirmar os direitos das pessoas com deficiência sem nenhum tipo de discriminação ou exclusão das pessoas, inserindo-as na sociedade. A Resolução CNE/CEB n 02 de 11 de setembro de 2001, institui as Diretrizes Nacionais para a Educação Especial na Educação Básica, que manifesta o compromisso do país com o desafio de construir coletivamente as condições para atender bem à diversidade de seus alunos (BRASIL, 2001, online). Pode-se dizer que essa Resolução representou um grande avanço na perspectiva da universalização do ensino e um marco na atenção à diversidade, na educação do Brasil, quando reafirma a obrigatoriedade da matrícula de todos os alunos na rede de ensino.

Após 2001, muitas leis, diretrizes e decretos foram publicados para garantir o direito, o acesso e a permanência dos alunos na escola regular. Dentre eles podemos citar algumas direcionadas a inclusão na educação: Lei no 10.436 de 247 de abril de 2002 dispõe sobre a Língua Brasileira de Sinais(LIBRAS); a Resolução do CNE nº 1 de 18 de fevereiro de 2002, essa define que as universidades devem prever em sua organização curricular formação dos professores voltada para a atenção à diversidade e que contemple conhecimentos sobre as especificidades dos alunos com necessidades educacionais especiais; a Portaria no 2.678 de 24 de setembro de 2002, ela vem para aprovar e normalizar o uso, o ensino, a produção e a difusão do Sistema Braille em todas as modalidades de ensino; Portaria MEC n $^{\circ}$ 976, de 05 de maio de 2006, dispõe sobre os critérios de acessibilidade aos eventos do Ministério da Educação, conforme decreto n 5296 de 2004; a Lei no 12.764, de 27 de dezembro de 2012, instituindo a Política Nacional de Proteção da pessoa com Transtorno do Espectro Autista; Lei n ${ }^{\circ} 13.146$ de 6 de julho de 2015, instituindo a Lei Brasileira de Inclusão da Pessoa com Deficiência (Estatuto da Pessoa com Deficiência); a Portaria normativa $\mathrm{n}^{\circ}$ 9, de 5 de maio de 2017, que altera a Portaria Normativa MEC nº 18, de 11 de outubro de 2012, e a Portaria Normativa MEC $\mathrm{n}^{\circ} 21$, de 5 de novembro de 2012, sobre a política de cotas.

Vale salientar o quanto a educação inclusiva avançou nos últimos anos ao que refere-se aos direitos da pessoa com deficiência, mas ainda temos muito que avançar na prática inclusiva referente a formação pedagógica inclusiva, as equipes multiprofissionais e sobre o atendimento educacional especializado (AEE) para que as leis possam realmente vigorar em prol da pessoa que necessita.

\subsection{Necessidade Educacional Específica (NEE) e Atendimento Educacional Especializado (AEE)}

Necessidades Educacionais Especiais (NEE) são caracterizadas por problemas na aprendizagem dos alunos, podendo ser em caráter temporário ou permanente. Alunos com NEE são aqueles com deficiência física, mental, sensorial (visual e pessoas com surdez parcial e total), transtornos gerais de desenvolvimento e com altas habilidades (superdotados) e etc.

Pessoa portadora de necessidades especiais é a que apresenta, em caráter permanente ou temporário, algum tipo de deficiência física, sensorial, cognitiva, múltipla, condutas típicas ou altas habilidades, necessitando, por isso, de recursos 
especializados para desenvolver mais plenamente o seu potencial e/ou superar ou minimizar suas dificuldades. No contexto escolar, costumam ser chamadas de pessoas portadoras de necessidades educativas especiais (Brizolla apud Stobäus; Mosquera, 2006, p. 244).

Para uma promoção de acesso a todos os alunos e oferecer as condições para uma educação completa, deve-se matricular alunos com deficiência, transtornos globais do desenvolvimento e altas habilidades nas escolas do ensino regular e ofertar a eles o Atendimento Educacional Especializado (AEE), e assim oferecer condições para uma educação de qualidade e excelência.

Podemos definir AEE como um serviço na Educação Especial que identifica, elabora e organiza recursos pedagógicos para uma acessibilidade que consiga eliminar empecilhos com uma plena participação dos alunos dentro das necessidades específicas. Assim o AEE completa/suplementa a formação para uma autonomia/independência dentro e fora da escola (SEESP/MEC, 2008).

O AEE, entre outros objetivos, tem como função identificar, elaborar e organizar recursos pedagógicos e de acessibilidade oferecendo uma plena participação dos discentes, dentro das suas necessidades específicas. Assim se complementa sua formação, propiciando autonomia, independência e socialização dentro e fora do ambiente escolar.

Os serviços e recursos dentro da educação especial podem ser considerados como aqueles que assegurem condições de promoção ao currículo através do acesso a materiais, espaços, equipamentos, sistemas de comunicação/informação e conjuntos de atividades escolares condizentes com as necessidades específicas de cada aluno.

Dentro das suas necessidades e considerando todas as suas limitações. Quanto ao atendimento relacionado a altas habilidades (superdotação) deverá se desenvolver atividades para um enriquecimento curricular e caso necessário procurar apoio e articulação dentro e fora do espectro escolar, tais como, instituições de ensino superior, profissionais de áreas como tecnologia, pesquisa, artes, esportes e quaisquer outros que se fizerem necessário.

As salas de recursos funcionais têm como objetivo o apoio e a oferta do AEE a ser prestado ao estudante com deficiência, transtorno global do desenvolvimento e as altas habilidades/superdotação que estão matriculados na sala de aula regular, garantindo o acesso e a participação ao que condiz a aprendizagem (SEESP, 2010, online).

\subsection{A inclusão em tempos da pandemia}

Muitas escolas desde março de 2020 tiveram a suspensão das aulas presenciais devido a Pandemia do Novo Coronavírus (Covid-19), assim as atividades remotas foram introduzidas para suprir a necessidade de dar continuidade ao ano letivo.

A suspensão das aulas presenciais substituídas pelo ensino remoto emergencial (ERE) impôs uma mudança radical de como a vida é conduzida pois o simples funcionamento dos sistemas de ensino, sobretudo na educação básica, impacta fortemente a rotina de milhões de estudantes, principalmente daqueles que apresentam alguma necessidade educacional específica como é o caso o estudante com deficiência (Magalhães, 2020, online).

A partir disso, surge o questionamento em relação a inclusão dos alunos que possuem alguma necessidade educacional.

O relatório da UNESCO (2020) ressalta que:

As respostas à crise da COVID-19, que afetou 1,6 bilhão de estudantes, não deu atenção suficiente à inclusão de todos os estudantes. Enquanto 55\% dos países de renda baixa optaram pelo ensino a distância online na educação primária e secundária, apenas $12 \%$ das famílias nos países menos desenvolvidos têm acesso à internet em casa. Mesmo abordagens com baixo uso de tecnologia não são capazes de assegurar a continuidade da aprendizagem. [...]No geral, cerca de $40 \%$ dos países de renda baixa e média-baixa não apoiam estudantes em situação de risco de exclusão. (UNESCO, 2020, p. $15)$. 
Assim, para Magalhães (2020) fica explicito que as ações governamentais não levaram em consideração a diversidade e a multiplicidade de necessidades desses alunos. O que muitas vezes já era difícil no presencial deverá ser adaptado para adaptar. Muitos eram alunos do atendimento educacional especializado (AEE) no contraturno do ensino regular acabaram perdendo o suporte escolar que possuíam.

Observa-se que coube à escola atender a uma parcela social que até então esteve excluída de seus projetos e planos de trabalho, ainda que estivesse presente em suas dependências, seja na classe especial, na sala de recursos ou na classe comum (Mendes, 2002, p.6). Cabendo assim ao professor da turma regular junto com o professor do AEE observar a construção dos materiais e o desenvolvimento das atividades dos alunos de inclusão para que esse aluno não seja excluído do sistema de ensino educacional.

Acreditamos que quando falamos de inclusão em tempos de pandemia ainda há muitos desafios a serem enfrentados para alcançar a demanda total dos alunos e as suas especificidades. Cavalcante e Jimenez (2020) deixa claro em seu trabalho que tal modelo de ensino remoto hoje praticado, em função da Pandemia do Coronavírus, não apresenta condições de aprendizado no que tange a atual legislação brasileira no que se referem a inclusão. São perceptíveis a falta de ação por parte dos órgãos governamentais para uma inclusão de fato no atual cenário vivido.

\section{Metodologia}

Optou-se neste estudo pela pesquisa de natureza qualitativa a qual a apresentação consiste na organização dos dados selecionados de forma a possibilitar a análise sistemática das semelhanças e diferenças e seu inter-relacionamento (GIL, 2010, p.175). De acordo com o objetivo traçado, o tipo escolhido de pesquisa foi a pesquisa exploratória, têm como principal finalidade desenvolver, esclarecer e modificar conceitos e ideias, tendo em vista a formulação de problemas mais precisos ou hipóteses pesquisáveis para estudos posteriores (GIL,2010, p. 27). Para esse autor as pesquisas exploratórias "têm como objetivo proporcionar maior familiaridade com o problema, com vistas a torná-lo mais explícito ou a constituir hipóteses (GIL, 2010, p.41).

Por conseguinte, essa pesquisa é um estudo de caso, que pode ser conceituado como um estudo empírico que investiga um fenômeno atual dentro do seu contexto de realidade, quando as fronteiras entre o fenômeno e o contexto não são claramente definidas e no qual são utilizadas várias fontes de evidência (Yin, 2005, p. 32).

Para discutirmos a temática realizou-se ainda uma pesquisa bibliográfica. Sendo os autores mais utilizados nessa pesquisa: Alves (2006), Mendes (2004), Glat e Oliveira (2003), Leis e diretrizes que embasam o tema. E, em relação aos procedimentos técnicos, escolheu-se o questionário semiestruturado. Para Gil (2010),

Pode-se definir questionário como a técnica de investigação composta por um conjunto de questões que são submetidas a pessoas com o propósito de obter informações sobre conhecimentos, crenças, sentimentos, valores, interesses, expectativas, aspirações, temores, comportamento presente ou passado (Gil, 2010, p. 121).

O questionário semiestruturado foi elaborado a partir dos autores pesquisados e foi aplicado via formulário Google Forms. Ele foi composto por 28 questões, sendo 8 questões dissertativas e 20 objetivas. O questionário buscou traçar o perfil dos entrevistados; a atuação nas aulas remotas durante a Pandemia do Novo Coronavírus e a interação com as famílias e alunos.

Os sujeitos de pesquisa foram 52 alunos da Pós-graduação em Docência, com ênfase na educação básica e educação inclusiva, do IFMG campus Arcos, turma de ingresso do ano de 2020 que são docentes em diversas redes de ensino. Ele foi enviado aos participantes por WhatsApp e por e-mail e ficou disponível no período de 03 a 20 de março de 2021.

Após a aplicação dos questionários eles foram analisados e categorizados de acordo com as perguntas e analisados com base na teoria estudada. 


\section{Resultados e Discussão}

Nesta seção discorreremos sobre os resultados, destacando que o questionário foi enviado para 95 estudantes da Pósgraduação em Docência, com ênfase na educação básica e educação inclusiva turma 2020, tendo retornado 52 estudantes o que representa $52,7 \%$ dos sujeitos pesquisados.

\subsection{Perfil dos professores}

Quanto ao perfil dos respondentes observa-se que maioria dos respondentes foi do gênero feminino com $74,5 \%$, seguidas pelo gênero masculino com $23,5 \%$ e $2 \%$ preferiram não declarar.

Em relação ao estado civil observou-se um maior número de respondentes casados $51 \%$, seguida pelos solteiros (a) $29,2 \% ; 5,9 \%$ responderam ter uma união estável e 3,9\% declararam ser separado/ divorciado/desquitado.

Quando questionados sobre a formação acadêmica $42 \%$ dos participantes declararam ter somente Graduação, seguidos por Especialização com 30\%, Curso Normal Superior 22\% e Pós-graduação Stricto Sensu 6\%.

Em relação a situação funcional dos respondentes 39,2\% relataram trabalhar na educação básica nos anos finais, 25,5\% trabalham na educação básica anos iniciais, $23,5 \%$ estão trabalhando no ensino médio e 11,8\% atualmente trabalham na educação infantil.

Observando o tempo de trabalho na área assinalada anteriormente 27,5\% diz ter de 5 a 10 anos, 17,6\% de 2 a 5 anos, $15,7 \%$ assinalaram ser estagiário, $13,7 \%$ têm mais de 20 anos de trabalho, 9,8\% de 10 a 15 anos, empatados com $7,8 \%$ participantes cada menos de 2 anos e de 10 a 15 anos. Observa-se então que 45,1\% dos respondentes têm até 10 anos de tempo de trabalho.

Ao serem indagados sobre a formação em educação inclusiva 62,7\% relataram não ter nenhuma formação nessa área e 37,3\% expôs ter tido alguma formação na área de educação inclusiva.

Em relação a ministrar aulas para alunos de inclusão, os respondentes afirmaram que 74,5\% dos participantes possuem alunos de inclusão e 25,5\% informaram não possuir alunos de inclusão. O que expõe uma dificuldade para os professores respondentes, pois, $62,7 \%$ afirmaram não ter formação em educação inclusiva, no entanto, 74,5\% têm alunos de inclusão.

Ao serem indagados sobre qual seria a necessidade educacional do seu aluno, a maioria, $34,2 \%$ assinalaram que o seu aluno possui alguma deficiência intelectual, 15,8\% afirmaram que o seu aluno possui o transtorno do espectro do autismo, $10,5 \%$ que os seus alunos possuem deficiência sensorial/ auditiva, 7,9\% que o seu aluno tem alguma deficiência física, 2,6\% possui altas habilidades ou superdotação, 2,6\% possui deficiência múltipla, 2,6\% síndrome de down, 2,6\% paralisia cerebral e o restante 7,9\% relataram que o aluno possui algum tipo de necessidade educacional, mas não relataram qual.

Os dados nos revelam que a maioria dos professores conseguem identificar as necessidades e deficiências dos seus alunos. Mas conforme Magalhães (2020) ainda é pouco explorado tal aspecto nos professores. A Pandemia do Novo Coranavírus traz à tona a grande necessidade de se desenvolver políticas públicas voltadas para esse público-alvo no intuito de se aprimorar ou incentivar a formação dos professores para a busca de ações que valorizem a inclusão com respeito às diferenças, identidades culturais próprias e a dignidade dos alunos.

\subsection{Ensino e Inclusão na Pandemia}

Em relação a utilização de ferramentas digitais nas aulas remotas 56,9\% dos participantes disseram utilizar as ferramentas digitais em suas aulas com os alunos que possuem alguma necessidade educacional e 43,1\% relataram não utilizar nenhuma ferramenta digital. Questionados sobre como eram realizados o ensino remoto alegaram receber apostilas prontas do Governo do Estado de Minas Gerais (PET - Plano de Estudo Tutorado) repassando aos alunos. Após o término do período 
estabelecido para as atividades, as recebiam e corrigiam quando enviados preenchidos, quando não preenchidos não se tomava nenhuma providência.

Ao analisarmos os recursos tecnológicos utilizados pelos professores na elaboração e preparação de aulas percebe-se que o principal recurso tecnológico utilizado é a internet, através de sites, com destaques para plataformas ou sites da instituição de ensino e/ou Secretárias e sites ou blogs direcionados para professores, contabilizando 62,17\% de utilização. O livro didático, seja na versão digital ou não, apresentou o menor percentual de utilização com 50\%. Tais dados nos permitem observar que os professores utilizam a internet como fonte básica de pesquisa e a utilização dos livros apresentam um declínio na utilização.

Buscamos entender quando se deu o início das atividades virtuais junto aos alunos com deficiências percebe-se que para 45,1\% no início do ensino remoto juntamente com os demais alunos, 29,4\% começaram depois que o ensino remoto já tinha começado para os outros alunos e 25,5\% não foi implementado qualquer tipo de atividade para os alunos com deficiência.

Os dados apontados nos revelam que a maioria dos alunos com necessidades especiais começaram o ensino remoto após os alunos das classes regulares (29,4\%) e para 25,5\% sequer começaram, ou seja, não estão sendo assistidos em suas necessidades de educação durante a Pandemia. Magalhães (2020) afirma que hoje estamos vivendo um cenário de práticas pedagógicas desconhecidas. E alunos e professores estão se adequando a modelos de ensino que são novos e com condições específicas. E muitos dos envolvidos ainda não estão sabendo lidar com tais dificuldades, muitas por falta de interesse de ambas as partes e outras por falta de recursos, sejam ele tecnológicos ou práticos para se implementar qualquer atividade. Podemos retomar aqui, o dado anterior onde os professores relatam não terem formação em educação especial, pode-se perceber que a Pandemia agravou e desvelou estas deficiências de formação para lidar com os alunos com deficiência.

Nesse aspecto percebemos que 25,5\% dos alunos não estão recebendo qualquer tipo de assistência educacional e não estão sendo assistidos em suas necessidades educacionais primarias. Silva, Bins e Rozek (2020) consideram que a atual situação vivenciada por esses alunos com deficiências é de total exclusão, sendo necessário uma rápida e efetiva alternativa para que tais condições precárias sejam alteradas através de políticas públicas e ou de assistência social em prol desses alunos.

Percebe-se que os alunos de inclusão não estão sendo acompanhados da forma correta. Simplesmente estão sendo relegados a uma educação excludente. Para Cury et al (2020) o aluno com alguma necessidade especifica não deve ter o seu direito a educação negado, mesmo em tempo de pandemia, o sistema deve ser inclusivo, ou seja, mesmo no ensino remoto, deve o aluno receber toda a assistência necessária para que possa se desenvolver educacionalmente.

Os professores respondentes apontam algumas justificativas em relação ao início tardia ou mesmo não início das aulas remotas para os alunos deficientes. Onde pode perceber três categorias de argumentos: a falta de acesso à tecnologia; dificuldade de acompanhamento pela família e/ou responsável e as atividades não adaptadas para os alunos com deficiência.

A escola é de periferia, com alunos sem acesso à Internet e computador, com inúmeras e extremas dificuldades. A maioria não consegue responder as demandas ou não se interessa. Os responsáveis pelos alunos de inclusão afirmam não poder ajudá-los, não tendo tempo ou habilidades suficientes (P 12)

As atividades desenvolvidas para os discentes em todas as disciplinas foram todas impressas, não fazendo distinção de alunos (P3).

$\mathrm{O}$ aluno especial tem que andar junto com sua turma com suas atividades adaptadas (P20).

As atividades pedagógicas e metodologias adaptadas e o acompanhamento dos alunos atípicos seguiram o mesmo fluxo dos alunos típicos (P5).

Dificuldade para engajar (P1).

Pode-se observar ainda uma culpabilização do aluno e da família pelos alunos não acompanharem o ensino, como fica evidente na fala dos respondentes P1 e P12. Mas os respondentes deixam claro não haver uma adequação do ensino ofertado aos alunos de inclusão. 
Quando abordados sobre a comunicação com as famílias e alunos de inclusão durante a Pandemia, os professores apontam que para 56,9\% existem sim dificuldades de comunicação com as famílias e os alunos e para 43,1\% não existe qualquer tipo de dificuldade. Perguntados como é dá a interação com as famílias de alunos de inclusão durante o período de aulas remotas, $47,1 \%$ responderam ocorrer às vezes o professor procura a família e às vezes é procurado pela família; $23,5 \%$ o professor sempre procura pela família do aluno; $21,5 \%$ relatam que não há contato com a família e 7,8\% a família me procura para saber do filho. Este dado de 21,5\% de famílias não terem contato com a escola é coincidente com o relato de que 25,5\% dos alunos de inclusão não terem começado a ter aulas no ensino remoto, como relatado pelas respondentes.

Segundo Souza, Borges \& Colpas (2020) a Pandemia é uma oportunidade de aproximação entre a escola e as famílias, uma vez que, as aulas passaram da escola para a casa dos alunos, criando uma oportunidade de os pais poderem acompanhar efetivamente o que os alunos estão aprendendo. Tal oportunidade só se deu através das tecnologias da informação e comunicação (TIC's) que possibilitaram um canal de comunicação da escola com os estudantes. Entretanto, tal canal deve ser de mão dupla, onde os professores e os pais possam se comunicar e acompanharem efetivamente o aluno. A pesquisa apontou que tal possibilidade ainda não vem sendo explorada da forma efetiva não se estabelecendo uma ampla comunicação com as famílias.

Ao se indagar sobre a periodicidade das atividades pedagógicas desenvolvidas no ensino remoto com os alunos de inclusão, 33,3\% dos professores abordados responderam 2 a 3 vezes por semana, 31,4\% nunca, 23,5\% uma vez por semana, 9,8\% ao menos uma vez por dia e $2 \%$ uma vez a cada 15 dias. Observa-se que paradoxalmente o número de alunos desassistidos nas atividades pedagógicas aumentaram, uma vez que 31,4\% dos professores nunca enviam at ividades para os alunos de inclusão. Os dados apontavam que 25,5\% dos alunos de inclusão não tinham começado a ter aulas no ensino remoto. Observa-se que ou as atividades são enviadas somente pelo professor AEE ou a exclusão é ainda maior.

Cury et. al (2020) relata que a pandemia tem desvelado a desigualdade existente no sistema educacional, de acesso à informação e tecnologia. E neste cenário a situação dos alunos de inclusão teve um impacto negativo significativo para os estudantes e professores. Os dados da pesquisa só nos demonstram o quão desigual ficou a educação especial, onde apenas 9,8\% dos respondentes enviam atividades diárias para os seus alunos com necessidades especiais. Observa-se que para agravar ainda mais a desigualdade de acesso ainda observa-se que a inclusão ocorre mais no discurso do que na prática, uma vez que, não se faz adequações do conteúdo e das formas de acesso dos alunos com deficiência a estes.

Ainda foi indagado sobre como é elaborado as atividades a serem repassadas aos alunos de inclusão e 57,7\% relataram que tais atividades são pensadas pela equipe (educativa), 23,1\% pelo professor exclusivamente e 19,2\% não há atividade para os alunos de inclusão.

Questionados se as atividades, quando existem, estão sendo avaliados, 50\% responderam que sim, e evidenciaram ser feita uma avaliação por competência; $26,9 \%$ não avalia e $23,1 \%$ têm apenas avaliações diagnósticas não sendo quantificada as atividades.

Em relação a continuidade do Atendimento Educacional Especializado (AEE) no período de Pandemia. 54,9\% dos professores respondentes assinalaram que o atendimento tem sido realizado por meio remoto e 33,3\% avaliam que não está ocorrendo, os demais respondentes com 1,9\% respectivamente, disseram que tem acontecido, mas com limitações; acontece de maneira presencial e não soube informar

Quanto a parceria entre o professor AEE e o professor regente de turma no ensino remoto, para 54,1\% existe uma parceria/ajuda do professor de AEE e 45,9\% dizem não existir qualquer tipo de parceria. Os dados aqui apresentados nos remetem a questões anteriores que mesmo com ajuda de professores de AEE o ensino remoto não está sendo efetivo para os alunos com deficiência. 
Acerca do conhecimento em Tecnologia Assistiva (TA) 54,9\% não tem conhecimento sobre a mesma e 45,1\% possuem tal conhecimento. TA é todo "recurso e serviço que contribuem para proporcionar ou ampliar habilidades funcionais de pessoas com deficiência e consequentemente promover vida independente e inclusão" (Sartoretto \& Bersch, 2020, online). Segundo as autoras a TA promove uma maior independência, autonomia e inclusão social dos alunos nas salas de aulas podendo ampliar a sua "comunicação, mobilidade, controle de seu ambiente, habilidades de seu aprendizado, trabalho e integração com a família, amigos e sociedade" (Sartoretto \& Bersch, 2020, online).

Canal \& Rozek (2020) defende que todos os alunos aprendam de forma igualitária. Todos devem possuir um acesso igualitário, com adaptações às realidades de acordo com as necessidades e singularidades de cada realidade escolar. Entretanto os dados apresentados nos remetem a uma realidade dispare onde 54,9\% dos entrevistados não tem conhecimento sobre os recursos da tecnologia assistiva para o trabalho com alunos de inclusão.

Cury et al. (2020) afirma que um sistema educacional inclusivo é aquele pensado a partir de princípios de equidade, que busca garantir uma educação de qualidade para todos. A educação inclusiva está distante da realidade do ensino remoto.

\section{Conclusão}

Sabe-se dos grandes e variados desafios enfrentados por todos, alunos e escola, para manter os estudantes próximos da escola e dentro de um contexto efetivo de aprendizagem durante a Pandemia do Novo Coronavírus, mas cabe aqui ressaltar que tais desafios são ainda maiores para a inclusão de alunos com deficiência.

Para se garantir tal inclusão em tempos de ensino remoto, é necessário o acolhimento do aluno e de sua família, dentro das suas necessidades e contextos específicos. Ter um olhar para as ferramentas de acesso, como internet, computador, celular, e em muitos casos o fornecimento de material de forma física e sua total disponibilização pela escola.

A pesquisa apresenta dados que expõem a fragilidade de acesso de educação neste momento, apontando que grande parte dos alunos com deficiência, estão fora de um contexto educacional na percepção do grupo de professores pesquisado.

Dentre os motivos para estes alunos não estarem sendo acompanhados pela escola, ou acompanhados de forma precária estão a falta de acesso à tecnologia; dificuldade de acompanhamento pela família e/ou responsável e as atividades não adaptadas para os alunos com deficiência. Ainda percebe-se a culpabilização dos alunos e da família acerca por este não acompanhamento.

Ressaltou-se que a formação do professor para o trabalho com a inclusão é fundamental, pois, grande parte dos professores respondentes não a tem e observa-se que este fato pode estar dificultando o trabalho do professor com este grupo de alunos, visto que as atividades e abordagens não estão sendo preparadas para estes alunos.

Percebeu-se que a Educação Inclusiva continua sendo um desafio enorme a ser enfrentado e este fato se tornou ainda mais evidente neste contexto. Observa-se assim, que a Pandemia do novo Coronavírus agravou o cenário de exclusão escolar para os alunos com deficiência.

Observa-se a necessidade de pesquisas mais amplas sobre esta temática, no intuito de lançar luz sobre ela fomentando seu debate e reinvindicações de maior investimento público para a inclusão dos alunos com deficiência e formação continuada de professores nessa área.

Trabalhos futuros sobre o processo de inclusão pós pandemia será de grande valia para o tema ora proposto. Para responder a seguinte pergunta: Pós pandemia do Coronavírus como está o processo de ensino e aprendizado dos alunos de inclusão? Salientamos que alunos de inclusão realmente devam ser incluídos nas salas de aula regular sendo dado assim, todo o suporte teórico e pedagógico a esses alunos. 


\section{Referências}

Bersch, R. \& Schirmer, C. (2005). Tecnologia assistiva no processo educacional. In: Brasil. Ministério da Educação. Ensaios Pedagógicos: Construindo Escolas Inclusivas. p. 87 - 92. Brasília.

BRASIL. (2001). Ministério da Educação. Diretrizes Nacionais para a Educação Especial na Educação Básica. Parecer CEB/CNE 17/2001, homologação publicada no DOU 17/08/2001, Seção 1, p. 46. Resolução CNE/CEB 02/2001, publicada no DOU 14/09/2001, Seção 1, p. 39. http://portal.mec.gov.br/cne/arquivos/pdf/CEB017_2001.pdf.

BRASIL. (2010). Ministério da Educação. Secretaria de Educação Especial. Orientações para a institucionalização da Oferta do Atendimento Educacional Especializado - AEE em Salas de Recursos Multifuncionais, implantadas nas escolas regulares. Brasília: MEC/SEESP http://portal.mec.gov.br/index.php?option=com_docman\&view=download\&alias=9936-manual-orientacao-programa-implantacao-salas-recursosmultifuncionais\&Itemid=30192

CNE/CEB no 4 de 2 de outubro de 2009. Institui Diretrizes Operacionais para o Atendimento Educacional Especializado na Educação Básica, modalidade Educação Especial. < http://portal.mec.gov.br/dmdocuments/rceb004_09.pdf>.

Canal, S. \& Rozek, M. (2020). Tempos de pandemia: reflexões sobre a escola, os sujeitos e suas diferentes necessidades. Revista Brazilian Journal of Development - BJD. doi: https://doi.org/10.34117/bjdv7n1-182

Cavalcante, M.S. A. et al. (2020). Educação inclusiva em tempos de pandemia. Anais VII CONEDU - Edição Online. Realize Editora.

Constituição da República Federativa do Brasil de 1988. <http://www.planalto.gov.br/ccivil_03/Constituicao/constituiçao.htm>.

Cury, C. R. J., Ferreira, A. M. F., Ferreira, L. G. F. \& Rezende, M. S. S. (2020). O Aluno com Deficiência e a Pandemia. Revista Instituo Fabris Ferreira.

Declaração de Salamanca. Sobre Princípios, Políticas e Práticas na Área das Necessidades Educativas Especiais. <http://portal.mec.gov.br/seesp/arquivos/pdf/salamanca.pdf>.

Decreto 3.298 de 20 de dezembro de 1999. Regulamenta a Lei no 7.853, de 24 de outubro de 1989, dispõe sobre a Política Nacional para a Integração da Pessoa Portadora de Deficiência, consolida as normas de proteção e dá outras providências. <http://www.planalto.gov.br/ccivil_03/decreto/d3298.htm>.

Decreto N. ${ }^{\circ}$ 3.956, de 08 de outubro de 2001. Promulga a Convenção Interamericana para a eliminação de todas as Formas de Discriminação contra a Pessoa Portadora de Deficiência (Convenção $<$ da http://www.planalto.gov.br/ccivil_03/decreto/2001/d3956.htm\#: :text=DECRETO\%20N\%C2\%BA\%203.956\%2C\%20DE\%208,as\%20Pessoas\%20Portadoras $\% 20 \mathrm{de} \% 20$ Defici\%C3\%AAncia>.

Decreto n 6.949 de 25 de agosto de 2009. Promulga a Convenção Internacional sobre os Direitos das Pessoas com Deficiência e seu Protocolo Facultativo, assinados em Nova York, em 30 de março de 2007. 〈http://legislacao.planalto.gov.br/legisla/legislacao.nsf/Viw〉.

Ferreira, A. B. de H. (2020). Mini Aurélio: o dicionário da língua portuguesa. Editora positivo. Atual, 856p.

Furlan, A. M. da S. (2014). Métodos e técnicas de ensino utilizados na sala de recursos multifuncionais: atendimento educacional especializado. Universidade Tecnológica do Paraná.

Lei $\mathrm{n}^{\circ}$ 12.796, de 2013. Altera a Lei $\mathrm{n}^{\circ}$ 9.394, de 20 de dezembro de 1996, que estabelece as diretrizes e bases da educação nacional, para dispor sobre a formação dos profissionais da educação e dar outras providências. < http://www.planalto.gov.br/ccivil_03/_ato20112014/2013/lei/112796.htm\#: :text=LEI\%20N\%C2\%BA\%2012.796\%2C\%20DE\%204\%20DE\%20ABRIL\%20DE\%202013.\&text=Altera\%20a\%20Lei\%20n\% C2\%BA\%209.394,educa\%C3\%A7\%C3\%A3o\%20e\%20dar\%20outras\%20provid\%C3\%AAncias>.

Lei $\mathrm{n}^{\circ} 10.098$, de 19 de dezembro de 2000. Estabelece normas gerais e critérios básicos para a promoção da acessibilidade das pessoas portadoras de deficiência ou com mobilidade reduzida, e dá outras providências. < http://www.planalto.gov.br/ccivil_03/leis/110098.htm>.

Lei $\mathrm{n}^{\circ}$ 10.172, de 9 de janeiro de 2001. Aprova o Plano Nacional de Educação $e$ dá outras providências. <http://www.planalto.gov.br/ccivil_03/leis/leis_2001/110172.htm\#: :text=LEI\%20No\%2010.172\%2C\%20DE\%209\%20DE\%20JANEIRO\%20DE\%202001.\& text=Aprova $\% 20 \mathrm{o} \% 20$ Plano $\% 20$ Nacional $\% 20 \mathrm{de}$, eu $\% 20$ sanciono $\% 20 \mathrm{a} \% 20$ seguinte $\% 20 \mathrm{Lei} \% 3 \mathrm{~A} \&$ text=10\%20Fica $\% 20$ aprovado $\% 20 \mathrm{o}$, com $\% 20 \mathrm{dura} \% \mathrm{C} 3 \% \mathrm{~A}$ $7 \% \mathrm{C} 3 \% \mathrm{~A} 3 \mathrm{o} \% 20 \mathrm{de} \% 20 \mathrm{dez} \% 20 \mathrm{anos}>$.

Lei 8.069, de 13 de julho de 1990. Dispõe sobre o Estatuto da Criança e do Adolescente e dá outras providências. <http://www.planalto.gov.br/ccivil_03/leis/18069.htm\#: :text=LEI\%20N\%C2\%BA\%208.069\%2C\%20DE\%2013\%20DE\%20JULHO\%20DE\%201990.\&text $=$ Disp $\%$ C3\%B5e $\% 20$ sobre $\% 20 \mathrm{o} \% 20$ Estatuto $\% 20 \mathrm{da}$,Adolescente $\% 20 \mathrm{e} \% 20 \mathrm{~d} \% \mathrm{C} 3 \% \mathrm{~A} 1 \% 20 \mathrm{outras} \% 20$ provid $\%$ C3\%AAncias.\&text=Art. $\% 201 \% \mathrm{C} 2 \% \mathrm{BA} \% 20 \mathrm{E}$ sta\%20Lei\%20disp\%C3\%B5e,\%C3\%A0\%20crian\%C3\%A7a\%20e\%20ao\%20adolescente.\&text=Nos\%20casos\%20expressos\%20em\%20lei,e\%20um\%20an os\%20de\%20idade>.

Magalhães, T. F. de A. (2020). Educação e Democracia em Tempos de Pandemia. Revista Interinstitucional Artes de Educar, 6, 205 - 221. https://doi.org/10.12957/riae.2020.53647 217.

MENDES, J. A. \& SCHMIDT, L. L. (2016). Alfabetização de crianças com deficiência matriculadas na rede regular de ensino. Poiésis, 10(18) 494- 510. doi: http://dx.doi.org/10.19177/prppge.v10e182016494-510

Portaria $n^{\circ}$ 1793, de 27 de dezembro de 1994. Recomenda a inclusão da disciplina "Aspectos Ético-Político-Educacionais da Normalização e Integração da Pessoa Portadora de Necessidades Especiais" prioritariamente nos cursos de Pedagogia, Psicologia e em todas as Licenciaturas. $<$ http://portal.mec.gov.br/arquivos/pdf/portaria1793.pdf>.

Secretaria de Educação Especial. Direito à educação: subsídios para a gestão dos sistemas educacionais - orientações gerais e marcos legais. < http://portal.mec.gov.br/seesp/arquivos/pdf/direitoaeducacao.pdf>. 
Research, Society and Development, v. 10, n. 7, e4710716380, 2021

(CC BY 4.0) | ISSN 2525-3409 | DOI: http://dx.doi.org/10.33448/rsd-v10i7.16380

Silva, K. W. da, BIns, K. L. G., \& Rozek, M. (2020). A educação especial e a covid-19: aprendizagens em tempos de isolamento social. Interfaces cientificas, 10(1), 124-136. https://doi.org/10.17564/2316-3828.2020v10n1p124-136

Sousa, G. R. de, Borges, E. M., \& Colpas, R. D. (2020). Em defesa das tecnologias de informação e comunicação na educação básica: diálogos em tempos de pandemia. Plurais Revista Multidisciplinar, 5(1), 146-169. https://doi.org/10.29378/plurais.2447-9373.2020.v5.n1.146-169

Stobaus, C. D.; Mosquera, J. J. M. (2006). Educação especial: em direção à educação inclusiva. 3 ed. Porto Alegre: EDIPUCRS, 2006. 